\title{
Patients' experiences and satisfaction with health care: results of a questionnaire study of specific aspects of care
}

\author{
C Jenkinson, A Coulter, S Bruster, N Richards, T Chandola
}

Qual Saf Health Care 2002;1 1:335-339

See end of article for authors' affiliations

Correspondence to: Dr C Jenkinson, Director of Research, Picker Institute Europe, Oxpens Road, Oxford OXI 1RX, UK: crispin.jenkinson@ pickereurope.ac.uk

\begin{abstract}
Objective: To determine what aspects of healthcare provision are most likely to influence satisfaction with care and willingness to recommend hospital services to others and, secondly, to explore the extent to which satisfaction is a meaningful indicator of patient experience of healthcare services.

Design: Postal survey of a sample of patients who underwent a period of inpatient care. Patients were asked to evaluate their overall experience of this episode of care and to complete the Picker Inpatient Survey questionnaire on specific aspects of their care.

Sample: Patients aged 18 and over presenting at five hospitals within one NHS trust in Scotland.

Method: 3592 questionnaires were mailed to patients' homes within 1 month of discharge from hospital during a 12 month period. Two reminders were sent to non-responders; 2249 (65\%) questionnaires were returned.

Results: Almost $90 \%$ of respondents indicated that they were satisfied with their period of inpatient care. Age and overall self-assessed health were only weakly associated with satisfaction. A multiple linear regression indicated that the major determinants of patient satisfaction were physical comfort, emotional support, and respect for patient preferences. However, many patients who reported their satisfaction with the care they received also indicated problems with their inpatient care as measured on the Picker Inpatient Survey; 55\% of respondents who rated their inpatient episode as "excellent" indicated problems on $10 \%$ of the issues measured on the Picker questionnaire.

Discussion: The evidence suggests that patient satisfaction scores present a limited and optimistic picture. Detailed questions about specific aspects of patients' experiences are likely to be more useful for monitoring the performance of various hospital departments and wards and could point to ways in which delivery of health care could be improved.
\end{abstract}

E valuation of healthcare provision is essential in the ongoing assessment and consequent quality improvement of medical services. Traditionally, assessments have ignored the reports of patients in preference to technical and physiological reports of outcome. More recently, however, healthcare systems have sought to achieve a balance in services that offer not only clinically effective and evidence based care, but which are also judged by patients as acceptable and beneficial. ${ }^{1}$ Health care which improves health only in some limited technical sense, but does not improve the quality or length of life, is not likely to be viewed as beneficial by patients. ${ }^{2}$ Interest has therefore grown not only in the assessment of treatment interventions by patients, but in the systematic evaluation of the delivery of that care. ${ }^{3}$ Most significantly, attempts have been made to determine the features of patient care that are likely to influence patient satisfaction.

Patient satisfaction is not a clearly defined concept, although most typically it appears to represent attitudes to care or aspects of care. ${ }^{4}$ While numerous questionnaires have been developed which ask people to rate aspects of care, such an approach has limitations. Attitudes to services do not tell us very much about the nature of those services. Surveys of patient satisfaction tend to elicit very positive ratings which are not sensitive to specific problems in the quality of care delivery. It has been argued that questionnaires should attempt to measure patients' experiences of their care, and then determine how such experiences are related to satisfaction. ${ }^{5}$ Patient satisfaction questionnaires have been criticised for failing to discriminate effectively between good and bad practice as they rarely ask patients about the value to them of their treatment. ${ }^{6}$ The Picker Institute has developed instruments which seek detailed information on patients' experiences of health care. ${ }^{78}$ These questionnaires are focused on specific dimensions of patient care-including information and communication, coordination of care, respect of patient preferences, involvement of family and friends, and continuity and transition. The questionnaires do not ask if patients are satisfied with these aspects of care but, instead, whether certain processes and events occurred during the course of a specific episode of care. Not only do the Picker instruments avoid asking if patients were satisfied with their care, but they address issues of particular salience to patients. The content of the measures is built upon qualitative in depth interviews with patients and focus groups. The questions included in the Picker survey reported here have been chosen to reflect concerns of patients.

The purpose of this study was (1) to determine what factors are most likely to influence satisfaction with care and willingness to recommend hospital services to others and (2) to explore the extent to which satisfaction is a meaningful indicator of patients' experience of healthcare services.

\section{METHODS}

Picker survey of patient experiences questionnaire

The conceptual basis and design of Picker questionnaires has been described elsewhere. ${ }^{9}$ The development of the initial instrument was undertaken at the Picker Institute in Boston, USA. Questions to be included in the instrument were devised on the basis of a literature review and in depth interviews and focus groups with patients to determine their priorities, and these were reviewed and put in questionnaire format by an expert advisory group. This produced a pilot version of the instrument which was tested using cognitive interviews with patients, and then redrafted and piloted. This instrument has 
Were you given enough privacy when discussing your treatment?

$$
1 \square \text { Yes }
$$

2 No

Did doctors talk in front of you as if you weren't there?

$$
\begin{aligned}
& 1 \square \text { Yes, often } \\
& 2 \square \text { Yes, sometimes } \\
& 3 \square \text { No }
\end{aligned}
$$

If you needed to talk to a doctor, did you get the opportunity to do so?

$1 \square$ Yes, often

2 Yes, sometimes

$3 \square$ No

$4 \square$ I had no need to talk to doctor

Did you want to be more involved in decisions made about your care?

$$
\begin{aligned}
& 1 \square \text { Yes, often } \\
& 2 \square \text { Yes, sometimes } \\
& 3 \square \text { No }
\end{aligned}
$$

Sometimes in hospital one doctor or nurse will say one thing and another will say something quite different. Did this happen to you?

$$
\begin{aligned}
& 1 \square \text { Yes, often } \\
& 2 \square \text { Yes, sometimes } \\
& 3 \square \text { No }
\end{aligned}
$$

Figure 1 Example items of those included in the questionnaire. Black boxes indicate responses coded as a "problem".

subsequently been used extensively in the USA since 1987, and formed the basis of the instrument used in the survey reported here. The appropriateness of the measure in the UK context was evaluated before its use. Patients, interviewed using focus groups, reported very similar concerns to those expressed in the USA, except that the issue of paying medical bills was not raised. ${ }^{10}$ The original measure was therefore modified by removing questions on payment and ensuring that the wording of questions in the UK version was semantically equivalent in that used in the US. An expert group of healthcare researchers, managers, and clinicians undertook this adaptation which was then assessed by patients in cognitive interviews in which they were asked to complete the measure and, while doing so, to comment on their understanding of the questions.

The questionnaire comprises 40 items which measure seven core dimensions: information and education; coordination of care; physical comfort; emotional support; respect for patient preferences; involvement of family/friends; and continuity of care. Each item is coded for statistical analysis as a dichotomous "problem score", indicating either the presence or absence of a problem. A problem is defined as an aspect of health care that could, in the eyes of the patient, be improved upon. An example of questions in the instrument and how they are coded as problem scores appears in fig l. Each domain is then scored from 0 (no reported problems) to 100 (all items coded as a problem).

A further two items were also included in the questionnaire booklet: the first (referred to as the "satisfaction" item) asked patients to rate their overall evaluation of care on a 5 point scale (with response categories of poor, fair, good, very good, and excellent). The second (referred to as the "recommendation" item) asked patients if they would recommend the hospital to others on a 3 point scale (with possible response categories of yes, yes probably, and no).

\section{Study design}

The data were collected by a commissioned postal survey of patients undertaken in 1999. Questionnaires were mailed within 1 month of discharge to the homes of patients aged 18 and over. Nine provider units were surveyed, covering five specialities in five hospitals in one NHS trust in Scotland. The patients were randomly selected from the Hospital Information System stratified by provider unit, age, and sex.

The sample size was based on previous experience of Picker survey instruments which suggested that approximately 300 respondents per provider unit would lead to narrow 95\% confidence intervals around individual item scores, assuming an average problem rate per item of $25 \% .{ }^{11}$ Assuming a response rate of $60-65 \%$, a sample size of 450 questionnaires per provider unit would produce more than sufficient data for analysis, leading to a planned total of 4050 questionnaires being mailed. However, the number of elderly patients admitted and discharged during the period of the study was small and hence the total number of questionnaires mailed was slightly less at 3592. Two reminders were sent to nonresponders; 2249 (65\%) questionnaires were returned.

\section{Statistical analysis}

Residuals were checked for normality to ensure that regression analysis could be performed on the data. Normality was checked by graphing the normal probability plot which did not detect any significant departure from normality. The regression analysis was undertaken to determine which of the seven dimensions of the Picker questionnaire (together with age, self-reported health, and sex) appeared to be significantly associated with patient satisfaction as the dependent variable. To determine whether assessment of global satisfaction provides an optimistic picture of healthcare experiences and consequently underestimates the number of problems encountered, the number of responses indicating problems on 


\begin{tabular}{ll} 
Table 1 & Admissions by specialty \\
\hline Specialty & $\mathrm{n}(\%)$ \\
\hline Medical & $577(25.7 \%)$ \\
Orthopaedic & $294(13.1 \%)$ \\
Surgical & $627(27.9 \%)$ \\
Elderly & $167(7.4 \%)$ \\
Other & $584(26.0 \%)$ \\
\hline
\end{tabular}

Table 2 Patients' satisfaction with their hospital care by willingness to recommend the hospital ( $n=2249)$

\begin{tabular}{lccc}
\hline & \multicolumn{3}{c}{ Willingness to recommend hospital } \\
\cline { 2 - 4 } & Yes definitely & Yes sometimes & No \\
\hline Overall satisfaction & $0(0)$ & $7(1.2 \%)$ & $31(18.7 \%)$ \\
Poor & $3(0.2 \%)$ & $69(12.1 \%)$ & $76(45.8 \%)$ \\
Fair & $99(6.9 \%)$ & $216(37.8 \%)$ & $44(26.5 \%)$ \\
Good & $530(36.8 \%)$ & $237(41.4 \%)$ & $13(7.8 \%)$ \\
Very good & $810(56.2 \%)$ & $43(7.5 \%)$ & $2(1.2 \%)$ \\
Excellent & $810(56)$ & & \\
\hline
\end{tabular}

the Picker questionnaire was broken down by overall satisfaction ratings. All correlations reported are Spearman coefficients.

\section{RESULTS}

The data set contained 2249 respondents, 1186 (52.7\%) women and $1029(45.8 \%)$ men. Thirty four (1.5\%) respondents did not answer the question relating to sex. The mean (SD) age was 60.9 (18.0) years (range 18-98). 920 (40.9\%) were planned admissions and $1116(49.6 \%)$ were emergency admissions. The specialties under which patients were admitted are shown in table 1.

Table 2 indicates the level of satisfaction reported by patients at their hospital visit. Most respondents described their experience as good, very good, or excellent. This finding is consistent with the results from the recommendation item in which $89.8 \%(\mathrm{n}=2109)$ of respondents indicated they would recommend the hospital to family and friends. Not surprisingly, the results from the two items were highly correlated $(\mathrm{rho}=0.64, \mathrm{p}<0.001 ; \mathrm{n}=2182)$.

Table 3 shows the mean scores on the seven dimensions of the Picker questionnaire, where zero scores indicate patients had no difficulties in the area and 100 indicates maximum problems. In general, physical comfort had the lowest (that is, the best) scores of all domains, with over $70 \%$ of respondents indicating no problems on that domain. Table 3 also shows the
Table 4 Spearman correlation of age, self-reported health status, and dimensions of the Picker questionnaire with global evaluation of health care and likelihood of recommending hospital to family/friends (all correlations significant at $p<0.001$ )

\begin{tabular}{lll}
\hline & Satisfaction & $\begin{array}{l}\text { Willingness to } \\
\text { recommend hospital }\end{array}$ \\
\hline Age & -0.11 & -0.17 \\
Self-reported health status & -0.17 & -0.11 \\
& & \\
Information and education & -0.45 & -0.40 \\
Coordination of care & -0.35 & -0.32 \\
Physical comfort & -0.43 & -0.39 \\
Emotional support & -0.56 & -0.50 \\
Respect for patient preferences & -0.53 & -0.47 \\
Involvement of family/friends & -0.39 & -0.46 \\
Continuity of care & -0.39 & -0.34 \\
\hline
\end{tabular}

Because of differences in direction in the coding of variables, a negative correlation indicates a positive relationship.

scores of patients broken down by those who would and would not recommend the hospital. For all dimensions of the Picker questionnaire there were substantial and statistically significant differences between the two groups $(\mathrm{p}<0.001)$.

Table 4 shows correlation coefficients of the dimensions of patient care, age, and self-reported health status with patient reported satisfaction with health care. Age and self-reported health status are often cited as major determinants of satisfaction and, in this instance, were found to be significantly correlated. However, the levels of correlation were low. Modest but significant correlations were found between satisfaction and overall assessment of health status (Spearman rho $=0.21, \mathrm{p}<0.001, \mathrm{n}=955$ ) and age (Spearman rho=0.10, $\mathrm{p}<0.002, \mathrm{n}=941)$. Higher correlations were found between dimensions of the Picker survey and satisfaction. Table 5 shows both standardised and unstandardised coefficients and levels of significance for age, self-reported health status, and sex (as a dummy variable), together with the seven Picker domains as independent variables and the 5 point satisfaction item as the dependent variable in a linear regression. An adjusted $R^{2}=0.48$ was achieved. The results suggest that the major determinants of patient satisfaction are physical comfort, emotional support, and respect for patient preferences $(p<0.00001)$. Age $(p<0.02)$, coordination of care $(p<0.01)$, involvement of family and friends $(p<0.0001)$, and continuity of care $(\mathrm{p}<0.001)$ also contributed to the model.

Another potential source of satisfaction is the number of items on which people report problems, so the total number of problems reported by each patient (range 0-40) was calculated. Patient overall satisfaction was highly correlated with the number of items completed (Spearman rho $=0.65$, $\mathrm{p}<0.001, \mathrm{n}=969)$. The association of level of satisfaction with

Table 3 Patients' evaluation of their hospital care broken down by dimensions of the Picker questionnaire $(n=1846-2249)$

\begin{tabular}{|c|c|c|c|c|c|c|}
\hline & \multicolumn{2}{|c|}{$\begin{array}{l}\text { All } \\
(n=1846-2249)\end{array}$} & \multicolumn{2}{|c|}{$\begin{array}{l}\text { Patients who would not } \\
\text { recommend hospital } \\
\text { ( } n=136-168)\end{array}$} & \multicolumn{2}{|c|}{$\begin{array}{l}\text { Patients who would } \\
\text { recommend hospital } \\
(n=1649-2014)\end{array}$} \\
\hline & Mean & SD & Mean & SD & Mean & SD \\
\hline Information and education & 22.9 & 16.1 & 46.4 & 26.6 & 21.1 & 25.2 \\
\hline Coordination of care & 18.8 & 21.4 & 34.1 & 23.8 & 17.7 & 20.8 \\
\hline Physical comfort & 8.5 & 16.7 & 27.5 & 25.1 & 6.9 & 14.7 \\
\hline Emotional support & 27.2 & 31.8 & 69.9 & 32.2 & 23.9 & 29.1 \\
\hline Respect for patient preferences & 30.9 & 28.6 & 64.0 & 25.2 & 28.6 & 27.2 \\
\hline Involvement of family/friends & 27.7 & 32.6 & 59.3 & 37.1 & 25.4 & 30.8 \\
\hline Continuity of care & 46.1 & 35.5 & 74.8 & 29.4 & 44.6 & 34.6 \\
\hline
\end{tabular}


Table 5 Results from a multivariate linear regression showing strength of association, indicated by standardised regression coefficients and unstandardised regression coefficients (and 95\% confidence intervals) between overall evaluation of care and age, self-reported health status, sex, and dimensions on the Picker questionnaire

\begin{tabular}{llll}
\hline & $\begin{array}{l}\text { Standardised } \\
\text { coefficients }\end{array}$ & $\begin{array}{l}\text { Unstandardised } \\
\text { coefficients }(95 \% \mathrm{CI})\end{array}$ & p values \\
\hline & & Constant $=4.77$ & $<0.02$ \\
Age (in years) & 0.05 & $0.002(0$ to 0.004$)$ & 0.27 \\
Self-reported health status & -0.02 & $-0.017(-0.49$ to 0.14$)$ & 0.60 \\
Sex & -0.01 & $-0.0185(-0.087$ to 0.050$)$ & 0.69 \\
Information and education & 0.01 & $0.000(-0.001$ to 0.002$)$ (NS) & $<0.01$ \\
Coordination of care & -0.05 & $-0.002(-0.004$ to 0.002$)$ & $<0.001$ \\
Physical comfort & -0.21 & $-0.001(-0.014$ to -0.10$)$ & $<0.001$ \\
Emotional support & -0.29 & $-0.009(-0.011$ to -0.007$)$ & $<0.001$ \\
Respect for patient preferences & -0.21 & $-0.007(-0.009$ to -0.006$)$ & $<0.01$ \\
Involvement of family \& friends & -0.06 & $-0.002(-0.003$ to 0$)$ & $<0.001$ \\
Continuity of care & -0.08 & $0.002(-0.003$ to -0.001$)$ & \\
\hline
\end{tabular}

Overall evaluation of care measured on a scale where $1=$ poor, $2=$ fair, $3=$ good, $4=$ very good, $5=$ =xcellent; male $=1$ and female $=2$.

Table 6 Number of issues affirmed as being unsatisfactory on the questionnaire broken down by overall assessment of the quality of care

\begin{tabular}{llllll}
\hline & Poor & Fair & Good & Very good & Excellent \\
\hline $\mathrm{n}$ & 17 & 80 & 159 & 402 & 403 \\
Minimum & 18 & 9 & 3 & 0 & 0 \\
Maximum & 31 & 34 & 27 & 25 & 24 \\
Mean & 25.05 & 22.81 & 14.50 & 9.91 & 5.44 \\
(SD) & $(4.24)$ & $(5.09)$ & $(5.88)$ & $(5.37)$ & $(4.09)$ \\
\hline
\end{tabular}

number of items completed is evident from descriptive statistics (table 6). However, even those who reported their health care as "excellent" indicated problems with their inpatient care. Table 7 shows the number of problems indicated on the Picker questionnaire, broken down by satisfaction. It is, for example, striking that $55.0 \%$ of patients who stated that their health care was excellent indicated four $(10 \%$ of the total number of potential problems) or more problems, while $13.2 \%$ indicated 10 or more problems-that is, they indicated problems on a quarter, or more, of the questions on the Picker survey.

\section{DISCUSSION}

These results are in agreement with previous research on patient satisfaction, but go further in that they indicate that more meaningful information is gained when patients are asked to report on specific aspects of their experience of care. It has been suggested that age and health status are major influences on patient satisfaction. ${ }^{3}$ This study suggests that age is an important factor in reported satisfaction, but self-reported health status was not. However, the most important determinants, as indicated by the regression, appear to be physical comfort, emotional support, and respect for patient preferences.
Evidence suggests that patients generally indicate that they are satisfied with care. ${ }^{12}$ The results reported here similarly find high levels of reported satisfaction. Furthermore, satisfaction is very highly associated with willingness to recommend to others the hospital in which they received treatment. However, many respondents who indicated that they were satisfied with their health care also indicated problems in aspects of their inpatient episode. Indeed, on the related dimension of willingness to recommend the hospital to others, problems were indicated on all dimensions of the Picker questionnaire for those patients who indicated they would be happy to do so. This seems to suggest that satisfaction with patient care and willingness to recommend a medical facility does not imply that all aspects of that care were successfully delivered. This confirms the results from other industries, such as civil aviation, where satisfaction scores may be high but customer complaints about specific aspects of the service continue. ${ }^{13}$

The evidence presented here would suggest that patient satisfaction scores, and the related issues of willingness to recommend a hospital to others, present a limited and optimistic picture. Detailed questions about specific aspects of patients' experiences are more likely to be useful for monitoring the performance of various hospital departments and wards and could point to ways in which healthcare delivery could be improved. Data such as these presented here indicate what areas of healthcare provision may be in need of change or improvement. Analysis of data at the level of the actual questions can help to pinpoint the exact issues needing to be addressed.${ }^{14}$ If satisfaction with the process of care is truly one of the goals of the health professions, then the way in which care is delivered must be evaluated through the eyes of the patient. It has only been relatively recently that health service providers have come to believe that patients can provide reliable judgements of their experiences of health and health care. ${ }^{15}$ The evidence provided here would suggest that it can be done in a way that provides meaningful information, which in turn can be used to improve service delivery.

Table 7 Number (\%) of problems indicated on the Picker survey broken down by
satisfaction with care overall
\begin{tabular}{lllllll}
\hline & Poor & Fair & Good & Very good & Excellent \\
\hline $4(10 \%)$ or more problems & $100 \%$ & $100 \%$ & $96.2 \%$ & $84.9 \%$ & $55.0 \%$ \\
$10(25 \%)$ or more problems & $100 \%$ & $98.7 \%$ & $73.6 \%$ & $39.4 \%$ & $13.2 \%$ \\
$20(50 \%)$ or more problems & $82.4 \%$ & $71.2 \%$ & $17.0 \%$ & $4.6 \%$ & $0.3 \%$ \\
\hline
\end{tabular}




\section{Key messages}

- Overall satisfaction with care is influenced by the number of areas in which patients experience what they perceive to be less than optimal care.

- Overall satisfaction provides an overoptimistic evaluation of patients' experiences of health care.

- Measuring experiences of health care, rather than satisfaction, provides a more meaningful indication of the quality of care received.

- The Picker Inpatient Survey, developed from interviews with patients themselves, can provide information on areas that may need improvement in the eyes of patients.

\section{What this paper adds to the topic}

The results are in agreement with previous patient satisfaction research but go further in indicating that more meaningful information is gained when patients are asked to report on specific aspects of their experience of care.

\section{Authors' affiliations}

C Jenkinson, Director of Research, Picker Institute Europe, Oxford and Director of Health Care Outcomes Research, Health Services Research Unit, University of Oxford, Oxford, UK

A Coulter, Chief Executive, Picker Institute Europe, Oxford and Visiting Professor of Health Services Research, University of Oxford

S Bruster, UK Manager, Picker Institute Europe

N Richards, Project Manager, Picker Institute Europe

T Chandola, Senior Research Fellow, Department of Epidemiology and Public Health, Royal Free and University College Medical School,

University College London, London, UK

The Picker Institute is a registered charity (no. 1081688) which undertakes research on health and medical care. It specialises in measuring patients' experiences of care and using this information to improve the provision of health services. Crispin Jenkinson holds a joint post as Director of Research at Picker with Director of Health Care Outcomes Research in the Health Services Research Unit in the University of Oxford. Angela Coulter is Chief Executive of Picker and a Visiting
Professor of Health Services Research in the University of Oxford.

Stephen Bruster is UK Manager and Nick Richards is Project Manager at Picker. Tarani Chandola holds a post at University College London and is not officially linked to Picker. Further information about Picker can be found at www.pickereurope.org

\section{REFERENCES}

1 Fitzpatrick R. The assessment of patient satisfaction. In: Jenkinson C, ed. Assessment and evaluation of health and medical care. Buckingham: Open University Press, 1997:85-101.

2 Jenkinson C. Measuring health status: a brief but critical introduction. Oxford: Radcliffe Medical Press, 1998.

3 Cleary PD, Edgman-Levitan S, Roberts $M$, et al. Patients evaluate thei hospital care: a national survey. Health Aff 1991;254-67.

4 Baker $\mathbf{R}$. Use of psychometrics to develop a measure of patient satisfaction for general practice. In: Fitzpatrick R, Hopkins A, eds. Measurement of patients' satisfaction with their care. London: Royal College of Physicians of London, 1993:57-76.

5 Cleary $\mathbf{P}$, Edgman-Levitan S, McMullen W, et al. The relationship between reported problems and summary evaluations of hospital care. Qual Rev Bull 1992; February:53-9.

6 Coulter A, Fitzpatrick R. The patients' perspective regarding appropriate health care. In: Albrech G, Fitzpatrick R, Scrimshaw S, eds. The handbook of social studies in health and medicine. London: Sage, 2000:454-64.

7 Coulter A. Quality of hospital care: measuring patients' experiences. J $R$ Coll Physicians Edinb 2002 (in press).

8 Bruster S, Jarman B, Bosanquet $\mathrm{N}$, et al. National survey of hospital patients. BM 1994;309:1542-9

9 Gerteis M, Edgman-Levitan S, Daley J, et al. Through the patient's eyes: understanding and promoting patient-centered care. San Francisco: Jossey Bass, 1993.

10 Bruster S, Lilley S-J, Lorentzon M, et al. Focus group reports from the Lothian University Hospitals NHS Trust. London: Picker Europe, 1999.

11 Picker Institute. Implentation manual. Boston, MA: Picker Institute, 1999.

12 Fitzpatrick R, Hopkins A. Problems in the conceptual framework of patient satisfaction research: an empirical exploration. Soc Health Illness 1983:5:297-311.

13 Bethune G, Huler S. From worst to first: behind the scenes of Continental's remarkable comeback. London: John Wiley and Sons, 1999.

14 Cleary P, Edgman-Levitan S. Health care quality: incorporating consumer perspective. JAMA 1997;278:1608-12.

15 Segal A, Roberts L. A comparative analysis of physician estimates and levels of medical knowledge among patients. Soc Health Illness $1980 ; 2: 317-34$ 